\title{
THE FLIPPED LEARNING STYLE AND ITS EFFECT ON THE LEVEL OF COGNITIVE ACHIEVEMENT OF SOME HANDBALL SHOOTING SKILLS
}

\author{
Maath Abdulkareem Fadhil , Prof. Dr. Mustafa Salah Aldeen \\ University of Baghdad / College of Physical Education and Sports Sciences
}

DOI: $10.37648 / \mathrm{ijrssh} . v 10 \mathrm{i} 02.025$

Received: $30^{\text {th }}$ March, 2020; Accepted: $20^{\text {th }}$ April, 2020; Published: $13^{\text {th }}$ May,2020

\begin{abstract}
The study aimed to define and modify a test for the cognitive achievement of some handball shooting skills for sophomores at the College of Physical Education and Sports Science as well as to identify the effect of using flipped learning educational units on the level of cognitive achievement of some types of handball shooting for the subjects of the study. The researchers adopted the experimental method and decided the number of study subjects to be (16) students for each experimental and control group. The main flipped learning experiment then executed in one educational unit per week for a period of (8) weeks. The results of the study indicated a significant effect on the results of the cognitive achievement test between the two groups in favor of the flipped learning experimental group.
\end{abstract}

\section{INTRODUCTION}

Inverted learning is one of the methods of effective or active education, and it is one of the modern alternative solutions to traditional learning that the teacher imposes by teaching the course at a specific time regardless of the extent to which students benefit and absorb the scientific subject, this method is based on the heart of the tasks of education between the class and the home, as it is The subject or subject is prepared in advance by the teacher in the form of a video in which the presentation, explanation and clarification are made in all aspects. The student reviews the basic material at home to achieve several goals, including economy in time and effort for the teacher to explain and clarify, in addition to providing more time for application and practice during the To study and correct errors through feedback, and also help to improve the cognitive outcome of students, and encourages them to use technology in an optimal way as each person bears responsibility for learning and in this way, mental and mental processes can develop in (thinking, analysis, comparison, conclusion, and problem solving).

Therefore, the importance of the study has emerged during the use of the inverted learning method, which the researchers hope to activate the student's role in the educational process by applying it and identifying its effect on the level of cognitive achievement of some handball correction skills for undergraduate students.

While the problem of research emerged through the researchers' observation that they are one of the faculty members of the subject, the presence of weakness in the cognitive achievement of students despite the availability of a good educational curriculum, and the presence of 
(IJRSSH) 2020, Vol. No. 10, Issue No. II, Apr-Jun

competent and highly experienced teachers in the field of specialization, except that this weakness in the level is caused by a lack of lessons Designated for handball within the weekly schedule, which leads to a limited time allocated to explanation and practical application during the time of the lesson and an increase in the number of students in one class. Hence, the researchers tried to address this problem and find temporary solutions so that researchers may reach satisfactory results to solve it, by using this method Knowledgeable.

As I have shown previous studies related to the subject of the study, including a study (Mazur, Brown, \& Jacobsen, 2015) that showed that this method contributed to improving communication skills between the teacher and the student, bridging the knowledge gap and providing feedback on the topic of learning outside the time of the lecture, which in turn was positively reflected in The high levels of student achievement in the various educational stages, whereas (Talbert, 2015) study shows that the inverted class turns the student's role from the negative future of information to the positive role and active participation in the educational process through knowing the educational content prepared by the teacher in advance and mastering it, thus giving them practical experience in Self-learning, which may consist of positive attitudes toward the teacher, while the study (AlZain, 2015) stated that "the inverted learning style takes into account the individual differences between learners, as the learner can watch the educational movie anywhere he chooses quickly, in time and how often it is appropriate for him using any available technique He has the ability to re-see the skill or explanation more than once each according to his level to reach the desired goal. "In a study (Al-Zahrani, 2015) whose results showed that the inverted class strategy in developing the level of cognitive achievement of the e-learning course had a clear impact on the level of student achievement When you touched The higher knowledge comes (application, analysis, synthesis, evaluation). As for the current study, the purpose was to identify the effect of inverted learning Table (1)
e-ISSN: 2249-4642, p-ISSN: 2454-4671

use on the mathematical side with regard to the motor skill which is aiming at the handball and what is related to it in terms of knowledge and the amount of information related to the nature and form of motor performance and how to implement The study found positive results in terms of increasing the level of cognitive achievement in favor of the experimental research sample.

As the aim of the study was:

- Defining and modifying a cognitive achievement test for some handball skills for the second stage students, College of Physical Education and Sports Science.

- Knowing the effect of using the educational units in the inverted learning method on the level of cognitive achievement of some types of aiming at the hand of the research sample.

\section{MATERIALS AND METHODS:}

The researchers used the experimental approach with two equal groups (experimental and control), as the research community, which represented the second stage students in the College of Physical Education and Sports Science at the University of Baghdad for the academic year (2018-2019) and the total number (190) students distributed over (7) people, The researchers made the deliberate choice of two divisions, after which the students who failed and were absent from the post-test are excluded, so that the research sample consists of (32) students distributed equally in each division by (16) students, as the research sample formed (12.84)\% of the research community, and The researchers randomly distributed the two educational methods Saliva lottery, while the sample was exploratory experiment (6) from outside the research sample, either building a sample for testing cognitive achievement was on the 3 people's (80) students of the total students.

The researchers used parity in the subject of cognitive achievement between the two research groups, as shown in the table below

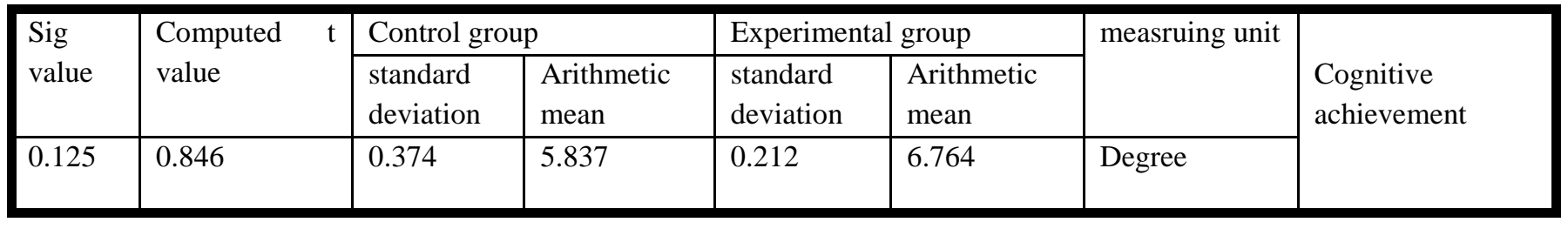


The researchers used the following methods in the study, which was (observation, personal interview, form to determine the validity of the cognitive test items for some handball shooting skills, as well as Arab and foreign sources, and a data dump form, the Internet, and a educational program prepared by the Adope Premier program) And the statistical means of the study. As for the tools, the special library tools were used in preparing cognitive achievement.

The researchers adopted the vocabulary determined for the second semester within the curriculum of the College of Physical Education and Sports Science for the academic year (2018-2019), which is prepared for the second stage of the handball lesson (aiming skill and its types), as a test was prepared for the purpose of measuring the cognitive achievement of the chosen types of correction (correction by an anchor step, With three steps, and to correct by jumping high and jumping forward), and presenting its paragraphs to a group of experts and specialists in the subject of the study to know the validity of each paragraph through their agreement, as shown in the table below, which indicated the extent of the experts' agreement on the paragraphs of the cognitive achievement test and its validity.

Table (2)

\begin{tabular}{|c|c|c|c|c|c|c|c|}
\hline \multicolumn{2}{|c|}{$\begin{array}{l}\text { The value of the } \\
\text { Chi square }\end{array}$} & \multicolumn{4}{|c|}{ The percentage of expert opinions } & \multirow[t]{2}{*}{$\begin{array}{l}\text { The number } \\
\text { of paragraphs }\end{array}$} & \multirow{2}{*}{$\begin{array}{l}\text { Paragraph } \\
\text { number in the } \\
\text { scale }\end{array}$} \\
\hline Tabular & $\begin{array}{l}\text { Calcul } \\
\text { ated }\end{array}$ & The ratio & Disagree & The ratio & Agree & & \\
\hline \multirow{4}{*}{3,84} & 11 & Zero \% & Zero & $100 \%$ & 11 & 9 & $\begin{array}{l}\text { 2- 3-5-8- } 9- \\
14-15-20-21\end{array}$ \\
\hline & 7.36 & $9.09 \%$ & 1 & $90.90 \%$ & 10 & 6 & $\begin{array}{l}\text { 7- } 10-12-18- \\
22-23\end{array}$ \\
\hline & 4.54 & $18.18 \%$ & 2 & $81.81 \%$ & 9 & 5 & $\begin{array}{l}\text { 4- 11- 16- 17- } \\
19\end{array}$ \\
\hline & 0.818 & $63.63 \%$ & 7 & $36.36 \%$ & 4 & 3 & 1- $6-13$ \\
\hline
\end{tabular}

After completing the formulation of the paragraphs and determining their validity by presenting them to a group of experts and specialists, and in order to ensure that the test is comprehensive of the scientific steps followed in construction, the researchers have prepared instructions for the cognitive achievement test that show how to answer its paragraphs, which are to be clear, easy and understandable as well as They increased clarity on how to answer by presenting an explanatory paragraph outside the test items and how to answer them, in addition to the need to answer all paragraphs in a manner that is appropriate for the laboratory's understanding and understanding, after which the researchers will conduct their exploratory experience on (6) students abroad. The two research samples (construction and application), and their purpose was to identify the most important difficulties that researchers face when applying the construction and application sample, to identify the extent to which students can understand the test clauses and their clarity as well as the integrity of their language and the way to formulate them. Then, the cognitive test was applied to a sample outside the research sample from the second stage students in the College of Physical Education and Sports Science and the University of Baghdad, who are (80) students.

After that, they perform statistical analysis of the cognitive test items, as follows:

First: Coefficient of ease and difficulty and coefficient of distinction of the paragraph: 
Table (3)

\begin{tabular}{|c|c|c|c|}
\hline $\begin{array}{ll}\text { Coefficient } & \text { of } \\
\text { discrimination } & \end{array}$ & $\begin{array}{l}\text { Difficulty } \\
\text { coefficient }\end{array}$ & Coefficient of ease & $\begin{array}{l}\text { Paragraph } \\
\text { number }\end{array}$ \\
\hline 0.52 & 0.34 & 0.65 & 1 \\
\hline 0.57 & 0.63 & 0.36 & 2 \\
\hline 0.57 & 0.59 & 0.40 & 3 \\
\hline 0.62 & 0.25 & 0.75 & 4 \\
\hline 0.45 & 0.78 & 0.21 & 5 \\
\hline 0.32 & 0.76 & 0.23 & 6 \\
\hline 0.42 & 0.55 & 0.44 & 7 \\
\hline 0.65 & 0.50 & 0.50 & 8 \\
\hline 0.50 & 0.32 & 0.67 & 9 \\
\hline 0.42 & 0.61 & 0.38 & 10 \\
\hline 0.52 & 0.44 & 0.55 & 11 \\
\hline 0.42 & 0.51 & 0.48 & 12 \\
\hline 0.50 & 0.25 & 0.75 & 13 \\
\hline 0.32 & 0.40 & 0.59 & 14 \\
\hline 0.42 & 0.25 & 0.75 & 15 \\
\hline 0.42 & 0.42 & 0.57 & 16 \\
\hline 0.42 & 0.53 & 0.46 & 17 \\
\hline 0.42 & 0.32 & 0.67 & 18 \\
\hline 0.47 & 0.63 & 0.36 & 19 \\
\hline 0.35 & 0.61 & 0.38 & 20 \\
\hline
\end{tabular}

Second: the internal consistency of the vertebrae (the correlation of the vertebral degree with the overall test score): 
Table (4)

\begin{tabular}{|c|c|c|c|}
\hline $\begin{array}{l}\text { Significance } \\
\text { level }\end{array}$ & Calculated value of $t$ & $\begin{array}{l}\text { Correlation } \\
\text { coefficient }\end{array}$ & $\begin{array}{l}\text { Paragraph } \\
\text { number }\end{array}$ \\
\hline 0.001 & 4.109 & 0.531 & 1 \\
\hline 0.000 & 3.949 & 0.516 & 2 \\
\hline 0.032 & 2.555 & 0.623 & 3 \\
\hline 0.000 & 3.695 & 0.491 & 4 \\
\hline 0.001 & 3.897 & 0.518 & 5 \\
\hline 0.081 & 3.405 & 0.468 & 6 \\
\hline 0.004 & 3.970 & 0.518 & 7 \\
\hline 0.003 & 3.813 & 0.489 & 8 \\
\hline 0.019 & 4.463 & 0.563 & 9 \\
\hline 0.016 & 4.795 & 0.591 & 10 \\
\hline 0.000 & 4.452 & 0.562 & 11 \\
\hline 0.000 & 4.305 & 0.549 & 12 \\
\hline 0.048 & 3.567 & 0.478 & 13 \\
\hline 0.044 & 3.414 & 0.462 & 14 \\
\hline 0.002 & 3.725 & 0.494 & 15 \\
\hline 0.000 & 4.408 & 0.559 & 16 \\
\hline 0.034 & 3.558 & 0.477 & 17 \\
\hline 0.018 & 3.868 & 0.508 & 18 \\
\hline 0.001 & 3.765 & 0.498 & 19 \\
\hline 0.022 & 3.826 & 0.504 & 20 \\
\hline
\end{tabular}

The value of the attributable tr (2.42) at the degree of freedom (79) and under the significance level (0.05)

The researchers point to the significance of the results for each of the vertebrae coefficient, the coefficient, ease and difficulty of the vertebrae, and their internal consistency. As for the psychometric properties of the cognitive test, the two researchers followed :Verify the test
The researchers used the differential honesty, by finding the coefficient of ease and difficulty of the paragraph, as indicated previously in Table (3), and the method of calculating the internal consistency of the paragraphs by finding the correlation coefficient between the degree of the paragraph and the total degree of the test as in Table (4), as well as finding the apparent honesty when Presenting the achievement paragraphs to experts and 
(IJRSSH) 2020, Vol. No. 10, Issue No. II, Apr-Jun

specialists to show their suitability, as shown in Table (2).

:Stability of the test

The two researchers used the midterm fractionation method, and the two researchers adopted the method of even and odd paragraphs and extracting the coefficient of stability by means of the correlation value.

Through this, the researchers were able to identify the extent of homogeneity of the two test items by using the (F) homogeneity test and confirm it, as the value of the mean, standard deviation, and variance of the first sample, respectively (6.9) (1.3) (3.9), and the mean value and standard deviation The variance for the second sample was respectively (7.08) (1.82) (4.04), and when applying the formula for fixed proportions, the calculated value of (f) reached $(1,083)$ which is less than the tabular value of (1.968) under the significance level (0.05) and at a degree of freedom (79), and the two researchers then performed the simple correlation coefficient (Pearson) between the two halves of the test, whose value was (0). 855). Thus, the value of the stability coefficient of the test was (0.82), and to identify the significance of the statistical stability coefficient, the researchers used the second test, correlation (TR), which showed its significance because the calculated value of TR, amounting to (8.364) is greater than its tabular value of (3.9) at a degree Freedom (79) and the significance level (0.05). This is an indication of the high stability of the cognitive achievement test. Thus, the cognitive test has become ready for the test.

After that, the two researchers conducted the pre-test of the research sample in the middle of March, by preparing the appropriate and appropriate place, taking into account the conditions for carrying out the test that was mentioned previously, then the assistant team distributed the forms to the research sample after reading the instructions for answering the test and listening to some questions posed by students.

Application of educational units for inverted learning:

The researchers adopted self-learning with the inverted learning method, as the researchers prepared educational units numbering (8 units) and over the course of (8) weeks in the light of the established curriculum for the experimental group, as the stages of implementing inverted learning were identified and the biggest burden
e-ISSN: 2249-4642, p-ISSN: 2454-4671

on the teacher is determined by determining the subject Analyzing the content and then preparing the video for the types of correction skill that were chosen within the vocabulary of the curriculum for this stage, by a player (model) from the national handball team, and photographing it from several directions at different speeds for the skill, its parts, stages of performance, and the mechanism of its implementation, then merging the voice of the explanation Allocated to them only Professor of the expert who teaches the course to the department, then treat it and add some effects to the editing programs, then print it on (CD) and distribute it to students, as well as upload it to a group group (Telegram), then direct the students to watch and listen to the lecture at home or Any place, time and number of times that suit him until the next educational unit, as well as practical application of what is seen with the guidance of the teacher during the learning unit and the calendar.

- The first part: - outside the lesson, and cognitive learning is self-dependent, based on the use of a computer or mobile phone for viewing by the mentioned means of communication, and a lecture is prepared for each lesson, consisting of a video of between (7-10) minutes that includes the motor performance of the skill that will be Her teaching is carried out by the model player, with a brief explanation of it by the course instructors, as well as asking questions at the end of the video.

The second part: inside the lesson, this part represents (testing, application, correction, evaluation) and includes: .- Quiz procedure for a period not exceeding (5D) about what was seen in the instructional video, in the form of multiple choice questions or true and false.

.Discussing the topic and asking questions -

As for the control group, its procedures were carried out according to the practice of the subject teacher, which is explaining the educational part for a period of (25) minutes, then the following is asking some questions for students to know the extent of response and understanding on the subject of the lesson, followed by a simple test (Quiz) for a period not exceeding (5D) ) At the end of the lesson.

Then the two researchers conducted the post test under the same temporal and spatial conditions and the conditions for carrying out the test. 


\section{RESULT AND DISCUSSION:}

Table (5)

\begin{tabular}{|l|ll|l|l|l|l|l|l|}
\hline SIG & $\begin{array}{l}\text { Calculated } \\
\text { value }\end{array}$ & \begin{tabular}{l} 
test after \\
\cline { 3 - 6 }
\end{tabular} & $\begin{array}{l}\text { standard } \\
\text { deviation }\end{array}$ & $\begin{array}{l}\text { Arithmetic } \\
\text { mean }\end{array}$ & $\begin{array}{l}\text { standard } \\
\text { deviation }\end{array}$ & $\begin{array}{l}\text { Arithmetic } \\
\text { mean }\end{array}$ & measruing unit & Variables \\
\hline 0.000 & 30.597 & 1.707 & 16.375 & 0.212 & 6.764 & Degree & $\begin{array}{l}\text { Cognitive } \\
\text { achievement } \\
\text { (experimental) }\end{array}$ \\
\hline 0.015 & 21.604 & 3.204 & 14 & 0.374 & 5.837 & & $\begin{array}{l}\text { Cognitive } \\
\text { achievement } \\
\text { (control) }\end{array}$ \\
\hline
\end{tabular}

Through the above table, which shows the results of the cognitive achievement tests for both groups and the significance of the differences between them, which showed the significance of the differences for both groups, and the researcher attributes this improvement that appeared to the first group (inverted learning) to the effectiveness of this method, which provided learners with a process of prior scientific understanding and knowledge through learning more On the content of the skill and its details in a suitable period before the lesson, and thus helped to draw initial coordinates in the brain for the skill to be learned and perceived from all sides and to reach the desired goal, in contrast to the traditional method, and this is what he emphasized (Ibrahim, 2017) "that The core of the process of cognitive processing in memory and the acquisition of a large amount of information through the senses used on the subject of learning, which makes there a great correlation between the stock in it and incoming to it and this leads to ease of awareness and understanding and reflects positively on the learning process, "and this is confirmed by (bloating, eclipse, and Hani, 2016) "Aspects of knowledge are one of the important goals of most of the physical education curricula for educated students. It is important things to know their rules, laws, kinetic performance and terminology for sports activity, as when the student turns away from practice he loses skill and fitness but can be established through It is enjoyable to enjoy watching if students have sufficient knowledge, so knowledge must be the first priorities and goals of any educational sports program by those responsible for it."

As for the control group, the researcher attributes this improvement to the appearance of the members of the research sample to the role of the subject teaching and the method followed in explaining and presenting the educational material according to his experience in education and his followings of scientific foundations in preparing the educational material and how it stimulates the motivations among learners and response to it all this contributed to improving the knowledge level of individuals This group, and this is what he emphasized (Al-Kazemi, 2002) that "one of the natural phenomena of the learning process is that there must be an development in the learning process as long as the teacher follows the proper steps and foundations for learning and teaching." View and discuss the results of cognitive achievement of some handball correction skills for the two research groups

\begin{tabular}{|c|c|c|c|c|c|c|c|}
\hline \multirow[t]{2}{*}{ SIG } & \multirow{2}{*}{$\begin{array}{l}\text { Calculated } \mathrm{T} \\
\text { value }\end{array}$} & \multicolumn{2}{|l|}{ Control } & \multicolumn{2}{|c|}{ Experimental } & \multirow[t]{2}{*}{ measruing unit } & \multirow[t]{2}{*}{ Variables } \\
\hline & & $\begin{array}{l}\text { standard } \\
\text { deviation }\end{array}$ & $\begin{array}{l}\text { Arithmetic } \\
\text { mean }\end{array}$ & $\begin{array}{l}\text { standard } \\
\text { deviation }\end{array}$ & $\begin{array}{l}\text { Arithmetic } \\
\text { mean }\end{array}$ & & \\
\hline 0.000 & 2.616 & 3.204 & 14 & 1.707 & 16.375 & Degree & $\begin{array}{l}\text { Cognitive } \\
\text { achievement }\end{array}$ \\
\hline
\end{tabular}

From the above table, which shows the results of cognitive achievement tests for both groups and the significance of the differences between them, which showed the significance of the differences and in favor of the experimental group at the expense of the control group, and the researchers attribute these differences to 
(IJRSSH) 2020, Vol. No. 10, Issue No. II, Apr-Jun

the effectiveness of the inverted learning style on the method followed by the teacher, and this superiority is due to the positive role through Provide accurate and prior scientific knowledge about the learned skill in terms of providing the video with explanation and special notes for this group, which can be used at any time, place and number of times that are appropriate to their level of understanding and awareness of the content that helped $p$ To enrich their mental processes, and this is confirmed by (Wissam Salah et al., 2018) "The most important characteristic of the inverted learning process in relation to the learner's role is to acquire higher levels of learning by gaining levels of knowledge outside the educational environment represented by (the home) such as understanding and remembering Perception and within the educational environment represented in (the class), higher thinking skills such as application, conclusion, and evaluation are acquired. Likewise (Al-Nuffakh, Kasoub, and Hani, 2016) stressed that the relationship between sports and cognitive development is a very close
e-ISSN: 2249-4642, p-ISSN: 2454-4671

relationship, as the first stages of learning skill Kinetics is called the cognitive stage, so we see that Cognitive processes and prior knowledge are involved in controlling the movement of action or performance in particular if they are supported by theoretical or imaginary content, given that the student stores theoretical and imaginary aspects in memory and retrieves them when they are needed when applying skill performance, which helps in the speed of learning mathematical skill.

\section{CONCLUSIONS:}

The researchers came out with conclusions:

- Inverted learning contributed to improving the cognitive level of some handball shooting skills for students.

- Inverted learning plays an important role in wishing the learner's intellectual and mental skills, such as observation, thinking, perception, analysis, and deduction.

\section{REFERENCES:}

- Mazur, A., Brown, B., \& Jacobsen, M. (2015, may 30). Learning Designs Using Flipped Classroom Instruction. Canadian Journal of Learning and Technology, 41(2), P.1-26. doi:https://doi.org/10.21432/T2PG7P.

- Talbert, R. (2015). Flipped Classroom. 18th Annual Legacy of R.L Moor and IBL Conference. Atlanta.

- Amal Kamal Al-Bajawi. (2006). The effect of individual and cooperative investigation strategies on acquiring communication and achievement skills in mathematics among middle school students in Jordan. PhD thesis, Amman Arab University for Graduate Studies.

- In the name of Al-Sarayrah, Khaled Al-Falih, Yahya Al-Smadi, and Firas Al-Salbiti. (2009). Learning and teaching strategies - theory and practice. Book World for Publishing and Distribution, Jordan.

- Hanan Asaad Al-Zain. (January, 2015). The effect of using the inverted learning strategy on the academic achievement of students of the College of Education with the support of Princess Noura bint Abdul Rahman. International Specialist Educational Journal, Vol. 4 (1), pp. 317. doi: 10.12816 / 0009241.

- Salman Abdul Wahid Ibrahim. (2017). Physiology and biology of cognitive functioning. Amman: Al-Manhaj House for Publishing and Distribution.

- Dhafer Hashem Al-Kazemi. (2002). The intertwined teaching method and its effect on learning and development through spatial organizational options for the tennis education environment. PhD thesis, University of Baghdad, College of Physical Education.

- Abdul Rahman Al-Zahrani. (January 2015). The effectiveness of inverted classroom strategy in developing the level of knowledge achievement of the e-learning course for educational students at King Bin Abdulaziz University. Journal of the Faculty of Education, Al-Azhar University, 2 (162), 471-501.

- Nizar Al-Nafakh, Firas Kassoub, and Ayman Hani. (2016). Cognitive tests in the mathematical field between theory and practice. Al-Najaf Al-Ashraf: Dar Al-Diaa Printing House.

- Wissam Salah, and others. (2018). Learning patterns and applications between the teacher and the learner. Babel: Dar AlSadiq Cultural Foundation. 